Anna Croon Fors and Mikael Wiberg:

\title{
Digital Materiality as Imprints and Landmarks: The case of Northern Lights
}

\begin{abstract}
:
In this paper a case is made concerning how important levels of media technology and new interactive textures affect urban landscapes. The case is based on experiences and empirical examples from a Scandinavian city (Northern Lights) in which levels of interactive infrastructures, mediated spaces, and places, are high, and in which accessibility and social inclusion traditionally have been strong components in societal and systems design. Our designerly approach discloses some of ways that the city is enacted by a new digital materiality. This materiality can only bee disclosed if the relationship between the city and ICT is understood as a meaningful whole - a totality - in this text illustrated by the notions of landmarks and imprints. Based on our case we suggest that it is possible to employ an ethical dwelling reflecting the endless, active and ongoing responsibility for the city and its interactive textures in everyday life.
\end{abstract}

\section{Agenda:}

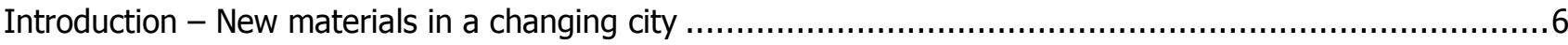

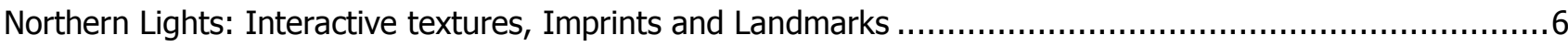

Designerly Approaching Materials and Ethics..............................................................................

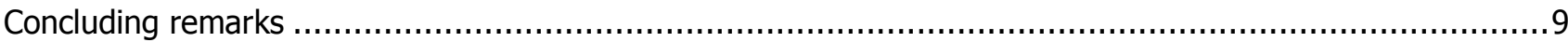

\section{Authors:}

\section{Dr. Anna Croon Fors:}

- Department of Informatics, Umeå University, 90187 Umeå, Sweden

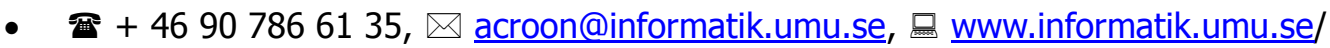

- Relevant publications:

- Croon Fors, Anna (Fortcoming 2010): The Matter of Meaning in Digitalization, AI and Society.

- Stolterman Erik and Croon Fors, Anna (2008): Critical HCI Research - A Research Position Proposal. Design Philosophy Papers, vol. 1.

Dr. Mikael Wiberg

- Department of Informatics, Umeå University, 90187 Umeå, Sweden

- -

- Relevant publications:

- Wiberg, Mikael, and Stolterman, Erik (2008): Environment interaction: Character, Challenges \& Implications for Design. Proceedings of the SigMobile and ACM conference "MUM 2008 - 7th international conference on Mobile and Ubiquitous Multimedia", ACM Press.

- Robles, Erica \& Wiberg, Mikael (2010): Texturing the "Material Turn" in Interaction Design, In proceedings of TEI 2010 - 4th international conference on Tangible and Embedded Interaction, January 25-27 2010, MIT Media Lab, Cambridge, MA, USA, ACM Press.

- Wiberg, Mikael (Forthcoming 2010) Interactive Textures for Architecture and Landscaping - Digital Elements and Technologies, ISBN: 1615206531, IGI-global, Hershey, USA. 


\section{Introduction - New materials in a changing city}

"... [the] thing is not merely what it is given to us to be, but reserves an 'otherness' in the sense of a dimension that withdraws from our grasp, and it is this withdrawal that allows the being to represent being within the totality..." Michael Lewis 2005, p.123

The city of today is changing. This might not come across as something new or unique, due to the basic fact that cities to a large extent are about change, growth, and development. Still, what we are facing is a new kind of change that has less to do with the city as a physical place and more to do with the city as a process and practice vis-à-vis to its being with ICT (Borgmann 2010; Croon Fors 2006; Greenfield 2006, Introna 2009; Lewis 2005 and McQuire, 2008).

For long, a history rich with various strands of approaches has been carved out to maintain ICT and the city as two distinct units of analysis. When the notion of "city" has been addressed from the perspective of ICT it has been about e.g. citizens augmented with ICT in the networked city (Mitchell, 2003), virtual or online cities, or simply "cyberspace" where new digital cities are established on the Internet. Similarly, when addressing implications of ICT for the city it has been about how ICT can bridge geographic distances, making the world smaller, or even flat (Friedman, 2005), and location irrelevant (Meyrowitz, 1985) instead of addressing the emergence of new practices and phenomenon arising within the "totality" of ICT and the city.

While one approach to the totality of ICT and the city could be to look into changes of social life in the city due to ICT, we take on an alternative approach. Our attempt is to search for, and identify, meaningful compositions of materiality that disclose and enclose significant interactive processes and practice in a city. This orientation of our research is motivated by 1) the current movement towards ubiquitous computing and how it blends into and fundamentally changes city life, 2) the ongoing digital reconfiguration of cities into "cities of bits" (Mitchell, 1995), 3) the rise of the "serve city" (Akbar, 2003), and 4) recent developments in the field of interactive architecture (Fox \& Kemp, 2009) with a huge potential to not only redefine our social world, but also to make the city responsive, active, sensitive, and in constant dialogue with its inhabitants.
Guiding our approach is among others Borgmann (1984; 1995; 1999; 2006; 2010) and Heidegger $(1971 ; 1977)$ in terms of the importance to compose unity in the apparent contradictory and disperse intertwining of informatics and the city. The advice offered by Borgmann (1999), orchestrating our concern is that:

"...we have to become again readers of text and tellers of stories... Stories are the spaces wherein pictures and mementos come to life and coalesce into a coherent picture of the past and a hopeful vision of the future. "Borgmann, 1999 p.231

Fundamental is also the suspicion that there is a need of a new ethical foundation as processes and practices are increasingly shaped by computation (Harman 2005, Introna 2009). So, contrary to upholding distinctions between the virtual and the real, the physical and the virtual, the media and the mediation the relationship between ICT and the city is in this paper conveyed in a designerly way (e.g. Borgmann 1995, Cross 2007, Heidegger 1971, Krippendorff 2006, Nelson \& Stolterman 2003 and Stolterman \& Croon Fors 2008). The designerly way and the differences it makes for concerns about ICT in the city will be discussed in a following section. But first a brief illustration of our case, Northern Lights and the meaningful wholes of interactive textures that are disclosed in our study. ${ }^{1}$

\section{Northern Lights: Interactive textures, Imprints and Landmarks}

The Northern Lights city was founded in the 17th century and was at the time one of the few gateways to northern wilderness. Since then the city has developed from slumbering county seat, via an expansive university, into a multi-facetted regional capital with a large industry sector and an expanding service sector.

Today the city is one of the largest growing cities in the north with approximately 100000 inhabitants, with an average age of 37 years and approximately $50 \%$ of the population with an academic degree. ${ }^{2}$ During the last ten years employment in private trade and industry has grown by more than $30 \%$

1 This study is part of a larger research programme on Digital Materiality investigating how new materialities emerge by interactive technologies.

2 For further details see http://www.umea.se. 
and has today overtaken the public sector in terms of the number of people employed. Within its population 130 nationalities are represented and the number of broadband connections per capita is among the highest in the world, not least thanks to the fact that city very early on built a fiber-optic metropolitan area network. In 2007 Northern Lights was named the IT Municipality of the Year. ${ }^{3}$

As inhabitant and researchers within this city we have seen the co-creation of landmarks, e.g. online social communities, geographically connected to the city square, as well as technological movements including e.g. "Open source" being used as a metaphor by the municipality to outline a direction for city development including the keywords of openness, curiosity and co-creation of cultural values to develop the city. ${ }^{4}$ We also acknowledge that the highly networked city composes itself through ongoing limelight of important textures, imprints and landmarks in the city.

In this paper we have chosen to highlight two aspects within The Northern Lights, Landmarks and Imprints. In this form we suggest that interactive textures in the urban cityscape presents itself as meaningful compositions through the everyday actions undertaking by the inhabitants of the modern city. We also suggest that further notice should be paid to such landmarks and imprints that characterize the interactive textures of modern cities. But, landmarks and imprints should not be seen as isolated and exclusive technical manifestations, but rather as indications of an evolving digitalized cityscape based on inhabitants' practice and processes.

Here, we define interactive textures as "digitalized materials, physically manifested, and capable of representing information and potentially also to scaffold interaction" (Wiberg, 2010). Our stance is further that we need to challenge conventional conceptions of technological rationality as constituted by values depriving people the sense of belonging to and sense of fulfillment and meaning (Croon Fors 2006). As a response, we are making the case that the interactive textures of Northen Lights can be seen as situated and realized in-between, and throughout the physical, the social and the digital. Our ambition is that these two aspects can illustrates the mutual shaping of the city and ICT as

3 For instance according to recent statistic $95 \%$ of the population has broadband access in their homes. See further http://www.umea.se.

$4 \mathrm{Http}: / /$ www.umea2014.se. totalities enhancing ethical considerations beyond instrumental rationality and closer to our focal concerns (Borgmann 1984).

Landmarks are often conceived of as a geographic feature used to support orientation and navigation within a particular place. In our case landmarks are also understood as such, both also layered with aspects of the intertwinement of physical, social and digital that by inhabitants' of the city are appreciated as tool for meaningful navigation and orientation. Further on, and for our case, the landmarks are the digital manifestations of the physical as it appear in the modern cityscape.

One example in Northern Lights is The Monkey Mountain, predating Facebook ${ }^{\mathrm{TM}}$ as THE most favorable social network site for the city's younger population, for most in their adolescence. ${ }^{5}$ Here teenagers elaborate on identity, and digital inhabitation creating new understanding on the sociality, norms and deviations amongst their peers. The Monkey Mountain is also a traditional landmark, a physical place centrally located in the city square, where many inhabitants, (preferable teenagers) meet, talk and dwell before embarking on various everyday activities. As a landmark The Monkey Mountain is a composite and blended whole. An aspect of the interactive texture in which physical, social and digital materials are co-created by its inhabitants.

Imprints are commonly used in the publishing industry used to distinguish, for example different printings, or the same edition produced by a different publisher or printer. But imprints in our sense are rather used as those aspects imparting a strong or vivid impression of something. In this respect imprints are in our case conceived of as the ways through which the digital manifest itself in the physical world, and also the impact that the digital have on the life in the city. Within the Northern Lights one such imprint derives from by the cities strong emphasis on public transportation, traffic calming infrastructures, as well as a well-developed infrastructure of dedicated roads for biking.

In our case, imprints, are illustrated by, The bikes and bikers, where of important aspects of the physical and social infrastructures in the city is augmented and reinforced by interactive installations, revealing, recounting and enhancing the city as a bikerfriendly city as well as highlighting the amount of bikers as a communal celebration on a daily basis in

5 http://www.apberget.se/ 
the city. Since 2005 the city has actively been working to enhance and stimulate more of its inhabitants to use bikes as their first hand mean of transportation between the home, work and school. Of the cities inhabitants $41 \%$ of its' inhabitants walk or bike to work and school, but the goal of the city is to increase this level to $70 \%$. To reach this goal a thorough investigation of the habits of biking has been conducted. Among the recent ways of encouraging people to use bikes is the installation of interactive installations highlighting the large community of bikers in the city. ${ }^{6}$

These interactive installations are within our case one rough example of an imprint, attempting to disclose a shared value using the interactive texture of digital material. At one location it has been shown that the average number of bikers during one day to be 6000 . However the imprint not only mediates the statistics of the city back to the officers at the municipality and its inhabitants. It also within the physical scaffolds, signals and re-acknowledges the common concern to increase the number of bikers in the city. This, through a physical imprint which constantly work as a reminder to the city inhabitants about the current status of this concern, or more generally as a physical extension of a common social norm guiding sustainability thinking in the city.

\section{Designerly Approaching Materials and Ethics}

From our brief examples it appears as if citizens of Northern Lights are embracing ICT, not only as a mediator in the city, but as a new materiality, i.e. as a character of being material and composition of matter, scaffolding inhabitation and navigating in a post digital age. Our suggestion is that we through the notion of imprints and landmarks are able to provide some insights to this new materiality allowing us to advance new and different ethical questions concerning the role that it plays in everyday life city processes.

Taking this as a point of departure we explore our case further in a designerly way. First by acknowledging the importance of the real and its relation to the process of something coming into existence (Borgmann 1995; 2006, Nelson \& Stolterman 2003).

6 An image on the interactive counter can for instance be found at:

http://www.nt.se/arkiv/2006/08/26/Norrk\%F6ping/147838/Cykelr \%E4knare-tar-plats-p\%E5-H\%F6torget.aspx
Secondly, by incorporating the thinking of Kripendorff (2006) on the stages from compositions of resources into services, to compositions of services, to "ecologies of artifacts" i.e. the composition of technologies into meaningful wholes. Finally, following Nelson and Stolterman (2003) that design has meaning when we can see how compositions are connected to other things that we value (ibid, $\mathrm{p}$. 273).

As a result of this approach we suggest the Heideggerian notion of dwelling can be applied to the ethical discourses concerned with ICT in the city (Borgmann 1995, Heidegger, 1971). Following this line of thinking we acknowledge that inhabitants in Northern Lights, in order to get along spatially and socially are composing new meaningful unities and wholes intertwined by ICT. Such wholes that we by introducing terms like imprints and landmarks are able to convey.

As such we promote an approach to the relationship between ICT and the city that is both appreciative of the artificial world, but also is considered to be something that we ourselves are responsible for having created. Consequently, following among others Introna (2009) and Harman (2008) one of the issues at stake is that ethical concerns of ICT beforehand are determined in anthropocentric manners. As such the moral significance of ICT in the city is presumed within an a-priori framework of values that we assume is associated to technology as means to particular ends (Borgmann 1984, Latour 2002).

For instance, Introna (2009, p.38) writes: "... the revealing of us as 'users' or 'manipulators' of tools and objects, is, although the most obvious disclosure, but one possible way in which our things disclose us." He continues: "In the world of 'standing reserve', we exclude the possibility of being otherwise..." (p. 41). This view is roughly what is referred to as the device paradigm (Borgmann, 1984:35-48). In Borgmann's (ibid) view the fundamental difference lies in the way that we relate to the world and experience the world. However, in Borgmann's view the device paradigm is also, but one, of the possible ways in which things appear to us.

Our designerly approach thus help us to formulate the concern we have with contemporary views on ICT and the City. With this approach it is possible to acknowledge that any design of technological artifacts is a design of our actual reality and that digital materiality will create experiences that are being 
valued not only as individual objects, but also as parts of a whole. As such, based on our approach, we recall the Heideggerian claim that any technological design also reveals reality, i.e., make us aware of the environment and the reality we live in and the kind of lives we live in certain ways. ${ }^{7}$ Basically, with our approach we are reminded that there is never a case where interactive textures or digital materials only can be seen as separable objects and as means. Rather all artifacts also "points to the larger context of their setting in nature, and call for attention, effort, skill and fidelity to regular practice, and invigorate individual and community life." (Strong \& Higgs, 2000, p.32)

Hence, with our case we like to open up for alternative ethical dwellings of relevance for what kind of humans, or inhabitants we would like to become in terms of being a part of interactive textures and digital materials. So, although not fully recounted, our case revolves around the importance of identifying meaningful wholes disclosed and enclosed inbetween, and throughout the physical, the social and the digital. The intention is thus to encourage us to become more mindful in our narratives on the interplay between the city and ICT, suggesting that our imagination of the moral complexion of contemporary culture is enhanced by uniting parts of important interactive textures (Borgmann 2006, Wiberg \& Stolterman 2008, Robles and Wiberg 2010).

As such we attempt to propose an alternative human-centered ethics by employing a designerly approach. That is, an ambition to recall the perspective given to us by Heidegger (1971, p.148): "We do not dwell because we have built, but we build and have built because we dwell, that is be- cause we are dwellers." So, in our case we have made an attempt to identify and disclose some interactive textures by referring to them as a new kind of meaningful totality in the city. Our attempt is based on the importance to appreciate the role of ICT in the city and at the same time acknowledge inhabitants in the city as the particular beings that they are, i.e. as parts of a larger intertwined physical, social and digital materiality (Introna 2009).

Accordingly our approach appreciate the materiality of interactive textures in terms of its enabling of

7 In the essay The Question Concerning Technology, Heidegger (1977) outline two different ways of approaching and understanding technology. This dual nature of ICT is also advanced in for instance Croon Fors (2006). Here we attend to the nautre of technology revealing when advancing the role and ethics of digital materiality in the city. remotely communicate information, and enabling the physical space to become active, queryable, and connected. Further on, our approach also appreciates the role and importance of the digital in the physical world, and the physical in the digital. That is, as an integrated part of the architecture of the modern cityscape. This kind of appreciation opens up for an ongoing ethical dwelling of what kind of processes and practices, inhabitants and cities we like to be.

\section{Concluding remarks}

In this paper a case has been made concerning how important levels of media technology and new interactive textures affect urban landscapes. Our case is based on experiences and empirical examples from a Scandinavian city (Northern Lights) in which levels of interactive infrastructures, mediated spaces, and places, are high, and in which accessibility and social inclusion traditionally have been strong components in societal and systems design.

From our case of how new digital materials changes and enables new city practices we conclude that rather than maintaining ICT and the city as two distinct units of analysis our designerly approach discloses new totalities for meaningful inhabitation and navigating in the city. Consequently, our designerly approach in conjunction with our experiences from the case of Northern Lights has also resulted in two tentative concepts, landmarks and imprints.

The research presented in this paper is motivated by movements towards ubiquitous computing, the rise of the "serve city", and recent developments in the field of interactive architecture. Through our research as reported in this paper we add to this scholarly understanding through the introduction of a new vocabulary capable of speaking not only to the digitalization of the city - imprints, but also to the ways in which the city becomes digitally rerepresented - landmarks. In this undertaking we think about this movement in terms of new interactive textures and a new digital materiality.

Further, based on experiences from our case study of the city Northern Lights and in conjunction with recent thought within ethics and technology an alternative to human-centred ethics becomes valid. Therefore our final tentative conclusion is that the two concepts of landmarks and imprints, not only are examples of how a city with highly interactive infrastructures are integrating interactive texture in 
societal and systems design, but also illustrates an emerging ethics of new materiality, capable of reminding us that there is no simple, easily drawn line between things and people - between ICT and the city. On the contrary, notions like imprints and landmarks can assist us in finding opening potentials for future ongoing work on how we should advance our ethical encounter with otherness inscribed in changing city processes and practices.

\section{References:}

Akbar, Omar (2003): Serve City - Interactive Urbanism, JOVIS Verlag, UK.

Borgmann, Albert (1984): Technology and the character of contemporary life. Chicago: University of Chicago Press.

Borgmann, Alberg (1995): Depth in Design. In Buchanan, R. and Margolin, V. (Eds.): Discovering Design. Explorations in Design Studies, Chicago: The University of Chicago Press.

Borgmann, Albert (1999): Holding on to Reality: The Nature of Information at the Turn of the Millennium. Chicago and London: University of Chicago Press.

Borgmann, Albert (2006): Real American Ethics. Chicago and London: University of Chicago Press.

Borgmann, Albert (Forthcoming, 2010): Enclosure and disclosure on content and form in architecture, $A I \&$ Society.

Croon Fors, Anna (2006). Being-with Information Technology, Umea University: Department of Informatics. (Doctoral disseration)

Cross, Nigel (2006): Designerly Ways of Knowing. London: Springer.

Fox, Michael \& Kemp, Miles (2009): Interactive Architecture, Princeton Architectural Press, New York.

Friedman, Thomas (2005): The World is Flat, Penguin Books.

Greenfield, Adam (2006): Everyware: The Dawning Age of Ubiquitous Computing, Peachpit Press, UK.

Heidegger, Martin (1971): Building, Dwelling, Thinking. In Hoefstader, A. (Ed.) Poetry, Language and Thought. New York: Harper \& Row Publishers.

Heidegger, Martin (1977): Question Concerning Technology and Other Essays. New York: Harper \& Row.
Introna, Lucas (2009): Ethics and the speaking of Things. Theory, Culture \& Society, vol. 26, pp. 25-46.

Krippendorff, Klaus (2006): The Semantic Turn; $A$ New Foundation for Design. Boca Raton, London, New York: Taylor \& Francis CRC Press.

Lewis, Michael (2005): Heidegger and the Place of Ethics. Being-with in the crossing of Heidegger's thought. London: Contiuum.

McQuire, Scott. (2008): The Media City - Media, Architecture and Urban Space, SAGE Publications Ltd.

Meyrowitz, Joshua (1985): No Sense of Place - The Impact of Electronic Media on Social Behavior, Oxford University Press.

Mitchell, William (1995): City of Bits - Space, Place, and the Infobahn, The MIT Press.

Mitchell, William (2003): ME++ The Cyborg Self and the Networked City, The MIT Press.

Nelson, Harold and Stolterman, Erik (2003): The Design Way: intentional change in an unpredictable world. Englewood Cliffs: Educational Technology Publications.

Robles, Erica \& Wiberg, Mikael (2010): Texturing the "Material Turn" in Interaction Design, In proceedings of TEI 2010 - 4th international conference on Tangible and Embedded Interaction, January 25-27 2010, MIT Media Lab, Cambridge, MA, USA, ACM Press.

Stolterman Erik and Croon Fors, Anna (2008): Critical HCI Research - A Research Position Proposal. Design Philosophy Papers, vol. 1.

Strong, David \& Higgs, Eric (2000): Borgmann's Philosophy of Technology. In Higgs, et al. (Eds.), Technology and the Good Life? Chicago: The Chicago University Press.

Wiberg, Mikael, and Stolterman, Erik (2008): Environment interaction: Character, Challenges \& Implications for Design. Proceedings of the SigMobile and ACM conference "MUM 2008 the 7th international conference on Mobile and Ubiquitous Multimedia", ACM Press.

Wiberg, Mikael (Forthcoming 2010) Interactive Textures for Architecture and Landscaping - Digital Elements and Technologies, ISBN: 1615206531, IGI-global, Hershey, USA. 